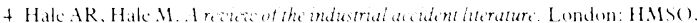
197

S Couper JB Vewbower RS, Kile RJ. An analwis of maior crrors and courment fulures in anesthesia management Considerations for prevention and detcition. Anesthestology 1984:60:34-42.

6 Sivak M. Iluman facters and highway accident causation: Some theoreticat consderations. Acodent Analyos and l'recentom 1981:13:61-4

Turner BA. Man-made disasters. 1,ondon: Wukcham Publications, 1978

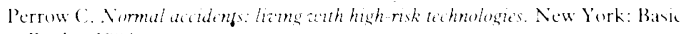
Berks, 198-

9 Reason J. Aheent-mindedness and cognitive control. In: Harri JE, Morris l'P:

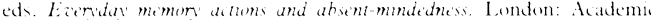
Press, 198.t:113.31.

10 Anderson RD). The phesician' contribution to hospital medication crrors Am f How Pharm 1971:28:18:25.

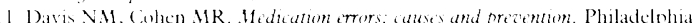

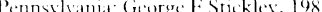

12. Long (i. The effect of medication distribution sistems on medication errors. Vurs $R_{i}=1982: 31: 182-4$

Is Bet\% RP. L.cW HB. An interdisciplinare methed of chassifing and menitorine medication crrors. im 7 Hosp Pharm 1985:42:1724-32.

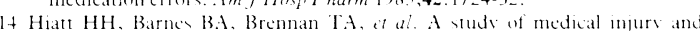
malpractice. Neciel lingl Y Hed 1989:321:480-t

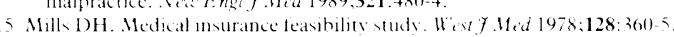

16 Department of Health and Secial Security. Hesplual inpatient enyury summer tablis. London: H.Miso, 1985

17 Office of Population Censuses and Survers. Report on comfutentul enquires

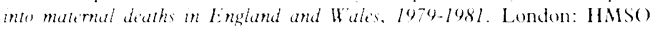
1986

Ix Lunn JN. Mushin WW. Mortalut assoctutid with andesthesta. Iondon: . Nufficld P'roninctial Hospitals Trust, 198

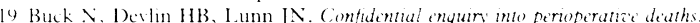
Londen: Nuffictd Procincial Hospitals Trust, 1987.

20) Dearden CH, Kutherford WH. The resuscitation of the severely injured in the accident and emergency department a medical audit. Inhury 1985:16 249.52

21 Eddy DM. Variations in phesician practice: the role of uncertaints. In: Dowic

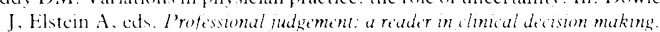
Cambridge: Cambridge Unisersits Press, 1988

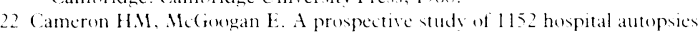
I1. Anakso in inaccuracies in clinical diagneses and their significance. 7 l'athol 1981:133:285-300)

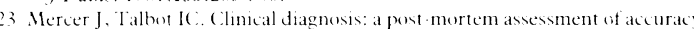

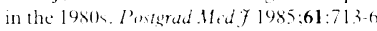

24 Adams ID, Chan M. Clifford PC et al. Computer aided diagnesis of acute ahdominal pain: at multicentre studv. Br.11ed 7 1986:293:800-4.

25 Driscoll PA. Vincent CA, Servant CJ, Audlex RJ. Use of advisers in the diagnosis and mathatement of abdominal pain in accident and emergenci departments, Bry Sur: 1988:75:1173-5

26 Durnford S. Junor heopulal dectors: tired and tested. Br. Hed 7 1988:297.

Deary IJ. Tate R. Beffects of sleep disruption on cognitive performance and mond in medical houre ufficers. Br Hed 7 1987:295:1513-6.
28 (Oron DI. (irucclier JH Adverse changes in mond and cognitie performance of house offlicers after night dutw. Br. 11tid $71989: 298: 21-3$

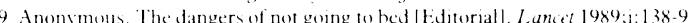
30 Firth-Cozens J. Emotional distress in iunier house officers. Br Med $1987,295: 533-6$

1 Pillowski L. ('Sullivan (i. Mental illness in doctors. Br Med f 1989:298 269.70

32 Cooper CI, Rout L, Faragher B. Mental health, joh satisfaction, and joh stress ameng general practitioners. Br.14: 7 1989;298:366-70.

Swansea Physcians" Audit Group. Audit of the qualits of medical records in a district general medicine unit. F $R$ Coll Physctums Lond 1983;17:208-12.

it Mansfield BC. How had are medical records? A review of the notes received hy a practice. 7 R (.oll (ien Pract 1986;36:405-6.

35 Leplat J. Rasmussen I. Analssis of human crrors in industrial incidents and accidents for improvement of work satets. Accid Anal Prea 1984:16:77-88.

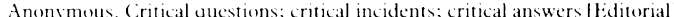
Lancet 198x:i:1373-4.

37 (iruser RH, Freis ED. A study of diagnestic errors. Ann Inem lled 1957:47:119-20.

38.11 K Kenna Fl' Duncan J. Brown ID Cognitive abilities and safetr on the road a re-examination of indicidual differences in dichotic listening and search for cmbedded tigures. Lirgonomics 1986:29:649-63.

39 McKenna FP. Accident proneness: a conceptual analssis. Aicd inal Pret $1981: 15: 65-71$

40) Ersenck MW . Atentwon and arousal. New York: Springer-Verlag, 1982.

4 Marteau TM, Winne (i, Kaye W, Exans TR. Resuscitation: experience without feedback increases confidence but not skill. Br. Med 71989 in press

2 McKenna, FP. Beharioural aspects of single-vehicte accidents. Trufte Enginetring and Control 1987;28:2801-5.

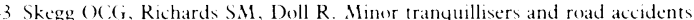
Br. Hidf 1979:1:917-9

H Lew $\mathrm{R}$. Alcoholism in house staff phrsicians: an occupational hazard. f()cup. 11:d 1986:28:79-81

5 Juntunen J, $A$ s S. Oikinuora $M$, Aarimaa $M$, Strid L, Kautu K. Dector drinking habits and consumption of alcohol. Br. 11ed f 1988:297:951-4.

to Balla JI. Iansck R, Elstein A. Bavesian diagnosis in presence of pre-existing discasc. Lum it 1985;1:326-9.

47 Colyuhoun WP. Rutentran/ J Studics of sutrcork London: Tavor and Francis, 1980

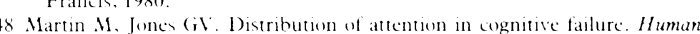
Léurming 1983:2:221-6

t9. Mentyre N. Popper $K$. The Critical attutude in medicine: the need for a new cthics Br.11:d 7 1983:287:1919-23

50 Christiansen-Szalanski JJJ, Buskrhead JBN. P'hysicians' use of probahilistic information in a real clinical setting. In: Dowie J, Elstein A. Professiomal judgement: a reuder in clincial decision making. Cambridge: Cambridge University P'ress, 1988:360)-73.

5 Simanowite $A$. Standards, attutudes and accountability in the medical profession. Lancel 1985;11:546-7.

Accopled 12 Siplember 1989

\section{Edinburgh Breast}

Screening Project

M Maureen Roberts, clinical

director

Correspondence to: Dr Joan

Austoker, CRC Breast

Screening Primary Care

Education Initiative,

Department of Community

Medicine and General

Practice, 2 Polstead Road.

Oxford OX2 6TN.

Br.Heity 1989:299:1153-5

\title{
Breast screening: time for a rethink?
}

\section{Maureen Roberts}

Dr M Maureen Roberts, clinical director of the Edinburgh Breast Screening Project since 1979, died of breast cancer on 9 Fune. We publish below her reflections on the care and welfare of women with the disease in Britain today, written shortly before her death. The list of references was added by the editor.

I am in reflective mood as I lie here in the sunshine at the end of my life. Breast cancer has caught up with me, after eight good years. It seems a common disease in Britain, and the evidence is strong that it is on the increase. Small wonder that people working with the disease desperately want to do something. Currently the main effort is in breast screening, with millions of pounds being put into a national programme, as recommended by the working group chaired by Professor Sir Patrick Forrest.

\section{What's the use of breast screening?}

I want to put the question, Are we going the right way to provide the best possible benefit?

First of all, screening is alwavs a second best, an admission of failure of prevention or treatment. As wo are unlikely to be able to prevent the disease what is required is successful treatment-and I don't mean even more aggressive adjuvant chemotherapy: I mean a treatment which works, which offers some kind of normal life. I don't want half promises of several years or a $50 \%$ chance of cure after surgery - it simply isn't good enough for women with the disease. As an example, Lippman believes that breast cancer could be the next human cancer capable of treatment and is working on innovative measures based on growth factors.' Others are using genetic approaches.

The next point to consider is, What can screening actually achieve? Two randomised trials, the Health Insurance Plan and the Swedish two county trial, showed a reduction in mortality of $30 \%$ in women offered screening. " Other trials, such as the Malmö, United Kingdom, and Edinburgh (unpublished) trials, found a non-significant reduction in mortality. We cannot ignore them, and it is not enough to say that our techniques weren't good enough a few years ago but are adequate now. We all know that mammography is an unsuitable screening test: it is technologically difficult to perform, the pictures are difficult to interpret, it has a high false positive rate, and we don't know how often to carry it out. We can no longer ignore the possibility that screening may not reduce mortality in women of any age, however disappointing this mav be.

Another problem is that screening is offered to only the small proportion of women aged 50-64, there being no evidence that it is of benefit to other women. When we calculate the number of women likely to benefit each year we find that it is a surprisingly small 
percentage of those who develop breast cancer. For example, of 2400 new patients with the disease seen annually in Scotland, 800 are aged 50-64, 270 will be invited for screening, 180 will attend, and 54 will benefit if there is a $30 \%$ improvement in mortality. Of course, it won't be like that because a larger number of cancers will be detected at the first visit and many fewer subsequently. Nevertheless, it is clear that the proportion of women with breast cancer who potentially may benefit is small. Some would prefer to exclude the over 65 s from this cost-benefit calculation, but why should we take such an approach to the elderly? We must also note that the benefit is a reduction in mortality. This is not offering any certainty of cure or normal life to the women who attend, merely a prolongation of years for a few. Not only that: we cannot predict who will have these extra years.

It seems now that the Forrest committee was premature in its recommendation. At the time screening certainly seemed more likely to be of benefit than it does now, but I cannot help believing that it was a political decision. The government is prepared to put a large amount of scarce resources into a national breast screening programme, yet is unwilling to take on the tobacco industry at a political level; this despite overwhelming evidence that a truly preventive programme would save thousands of lives each year from lung cancer and other diseases. It was clearly a matter of politics, a decision taken in an election year and now out of perspective.

\section{Might breast screening actually be detrimental?}

I have to go on and ask the next question: If screening does little or no good could it possibly be doing any harm? We are all reluctant to face this.

Firstly, I'm thinking about the false positive rate. One in 10 women are being asked to come back for further investigations, which is an unacceptably high proportion. It clearly does not cause all women psychological harm, but it is traumatic for many. In most cases it is also unnecessary.

Some $10 \%$ to $17 \%$ of all the cancers will be diagnosed as non-invasive. The screeners are delighted, but non-invasive cancer is a difficult condition for women, and no studies have been done about their thoughts and feelings. We do not know how much it represents an overdiagnosis of cancer, nor do we know its natural course or how to treat it.

For most women who have invasive cancer diagnosed they become "patients" like other women. The difference is that they did not discover the problem, it was discovered for them. There is also an undeniable if subtle pressure on them to be grateful for this. Undoubtedly many are grateful, but no studies have been done to find out what women feel and think. Neither do we know how these women cope with recurrence. After all, they were almost promised (if only by implication) a good outcome if they attended for screening.

The current national programme seems prestigious and has consequently attracted many good people who want to set up a high quality service. Though standards will vary across the country, quality control is being taken seriously. It is possibly in danger of becoming a highly technological service. There is also an air of evangelism, few people questioning what is actually being done. Are we brainwashing ourselves into thinking that we are making a dramatic impact on a serious disease before we brainwash the public? Many thousands of women will be invited for screening and those who attend are said to be "compliant." The compliance rate is not very high and I wonder what plans are being made to try to raise it.

I hope very much that pressure is not put on women

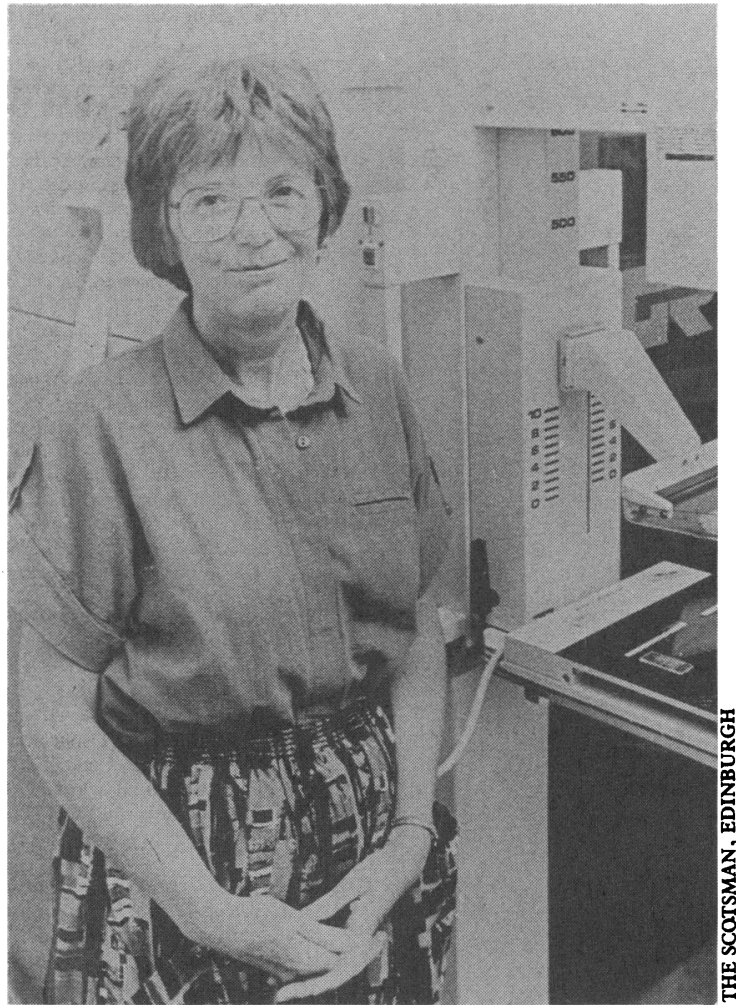

Maureen Roberts

to attend. The decision must be theirs, and a truthful account of the facts must be made available to the public and the individual patient. It will not be what they want to hear. They should be told that the test is to detect cancer while it is still small; that we don't know how much it can influence mortality but there is up to a $30 \%$ chance (though maybe much less) that it may prolong life; that the test does not detect all cancers, some of which may appear in the next three years; and that it can indicate only what the breasts are like today and cannot predict whether breast cancer will develop in future. In addition, we do not know how to treat breast cancer. There is no successful treatment; different surgeons will carry out different procedures. Only a minority of women will be given this result, however, and those who are normal can feel suitably reassuredexcept that they must remember that they can develop the disease at any time: screening is not prevention.

In view of all this it is difficult to know how to propose a health education programme for women. But the currently expressed or strongly implied statement that if women attend for screening everything will be all right is not acceptable. Modern ideas concentrate on healthy living rather than the search for disease. How to present screening in this context needs further research, which should be a priority. Meanwhile, crucial, scarce resources have been set aside until the end of the century to carry out statistical trials of screening which have been deemed important. It cannot be coincidence that the age and social class of those men who are influential in decision making are similar to those of their wives who appear to be at greater risk of the disease and also have the best chance of benefiting from screening. I'm sure this is entirely subconscious, but it must be why breast screening research has been so readily and expensively funded, possibly to the detriment of other, equally serious problems.

\section{Treatment policies}

I'd like to turn now to the treatment of women found to have cancer. In the absence of a successful procedure surgeons will carry on treating the small invasive 
tumours found on screening by mastectomy or local excision with conservation of the breast. Policies will vary, but it has already been expressed by many surgeons that "as we should give these women the best possible chance they should have mastectomy." Others will believe in conservation and use it as a bonus point for screening - "you save your breast if the tumour is found when it is small."

As no one knows how to treat non-invasive cancer many surgeons will advocate mastectomy and many women may prefer this. On the other hand, a national trial is being proposed based on conservation and systemic measures. The implication is that treatment will be different in different parts of Britain.

\section{What's to be done?}

I've drawn a dismal picture of screening, but it can be improved. I believe that the first thing is to create a nationwide, high quality diagnostic service for breast disease for women of all ages. The new screening clinics could form the basis. They require good clinical staff and surgical back up, cannot be radiological alone (though quality of mammography is of extreme importance), and must offer easy access for women and general practitioners. Clinicians, preferably women, would gain experience of the whole range of breast disease and its management.

The clinics should be run firmly in the context of health care and be sympathetic, open, and truthful, so that women can discuss problems with ease. A programme needs to be set up to encourage women to attend early, to try to reduce the number who currently present with inoperable disease $(35 \%)$. Women could be made to feel that these clinics (or centres) are their own. As women, especially older women, feel vulnerable to a variety of conditions other services should be offered. The extreme gratitude expressed by women at the Edinburgh Breast Screening Centre, the Woman's Health Shop in Edinburgh, and during the health education campaign conducted as part of the Edinburgh randomised trial of screening for breast cancer showed that they appreciate the services which are offered.

As far as treatment is concerned, surgeons must recognise that they have none and should try to design policies which are consistent so that women aren't treated by different methods depending on where they live. This means that communication is all important. Proper, truthful accounts of diagnosis, screening, treatment, and aftercare must be written and made available everywhere, so that women become well informed and, most important, start to take part in the decision making process for themselves. All the options should be given and the woman should decide if she so wishes.

Finally, it seems that priorities in resource allocation and research should change. I will leave aside the issues of prevention and the search for successful treatment. Meanwhile, the 24000 women who develop breast cancer each year in Britain require a first class diagnostic and therapeutic service, which should include research to provide necessary psychological back up. New psychological methods designed to improve quality of life (and, indeed, not impossibly quantity of life)-for example, self growth and visualisation, as well as more conventional approaches-should all be considered. More psychological research is required in the screening programme itself, particularly to establish the possible harmful effects on those with cancer. The 15000 women a year in Britain who need care for recurrent disease must not be forgotten.

\section{Conclusion}

I believe that a rethink is required before the programme goes much further. I feel sad to be writing this; sad because naturally after so many years I am sorry that breast screening may not be of benefit. I am also sad to seem to be critical of the many dear and valued colleagues I've worked with over the years, particularly those who have made such a magnificent contribution to the care and welfare of women with breast cancer. But they will recognise that I am telling the truth. I ask them to bring breast cancer screening into its proper perspective and ask again what we really wish to achieve in terms of benefit for women with the disease.

1 Lippman ME. Steroid hormone receptors and mechanisms of growth regulatio of human breast cancer. In: Lippman ME, Lichter AS, Danforth DN, eds. Diagnosis and management of breast cancer. Philadelphia: W B Saunders, 1988:326-47

2 Shapiro S, Venet P, Strax P, Roeser R. Ten to fourteen year effect of breas cancer screening on mortality. $\mathcal{F} N C I$ 1982;69:349-55.

3 Tabar L, Fagerberg G, Duffy SW, Day NE. The Swedish two county trial of mammographic screening for breast cancer: recent results and calculation of benefit. I Epidemiol Community Health 1989;43:107-14.

4 Andersson I, Aspegren $\mathrm{K}$, Janzon $\mathrm{L}$, et al. Mammographic screening and mortality from breast cancer: the Malmo mammographic screening trial. Br Med f 1988;297:943-8.

5 UK Trial of Early Detection of Cancer Group. First results on mortality reduction in the UK trial of early detection of breast cancer. Lancet $1988 ;$;i:411-6.

(Accepted 14 fuly 1989)

\section{ANY QUESTIONS}

In a small town in India we use industrial oxygen in place of medical oxygen. What are the risks, if any, of this substitution?

Oxygen for medical and industrial use is prepared by compressing air and cooling it until liquefied to allow fractional distillation to separate oxygen from nitrogen and the inert gases. Medicinal oxygen prepared in the United Kingdom is over $99 \%$ pure, with nitrogen and inert gases constituting the major part of the impurity. Contaminated gases that might harm patients, carbon dioxide, carbon monoxide, and oxides of nitrogen, are reduced to minute concentrations by the fractionation process. ${ }^{1}$

Gas for industrial use may be less pure than medicinal oxygen. A colleague who used industrial oxygen for anaesthetic purposes in India for 20 years assures me that, though analyses showed some $4 \%$ of impurities, nitrogen and the inert gases accounted for most of them.

Industrial oxygen might cause harm in two ways. Firstly, in any application, given that the oxygen concentration is $96 \%, 4 \%$ less oxygen will be delivered than shown on the flowmeter. For anaesthetic applications oxygen is invariably used at greater concentrations than is strictly necessary, so that the small fall in concentration would not result in hypoxaemia; $30 \%$ oxygen concentration would fall to $28.8 \%$, way above concentrations that might induce hypoxaemia. The most critical application of oxygen treatment is to reduce hypoxaemia in respiratory failure. Here $24 \%$ oxygen may be used to increase arterial oxygen saturation while reducing the risk of carbon dioxide retention. A $4 \%$ fall in oxygen concentration of the gas driving the venturi mask would have a marginal effect only on the oxygen concentration delivered. Secondly, the source of industrial oxygen might be contaminated with substances that could harm patients. I have indicated that the distillation process removes such contaminants, and my colleague never experienced problems attributable to such contamination. This suggests that the risk is insignificant. Nevertheless, any doctor using industrial oxygen should arrange for analysis of a sample, and if contaminants other than nitrogen and the inert gases were present in concentrations of more than a few parts per million another source of oxygen should be sought. In particular, oxygen concentrators are proving to be efficient and economical in developing countries.

Though availability and cost have undoubtedly led to the use of industrial oxygen one other benefit related to its use is that the $4 \%$ of nitrogen and inert gases present may help to prevent the closure of alveoli associated with the use of gases that can be totally absorbed-namely, $100 \%$ oxygen and nitrous oxide. - J M CUNDY, consultant anaesthetist, London

1 Grant WJ. Medical gases; their properties and uses. Aylesbury: HM and M Publishers, 1978:73-93. 